\title{
CONSUMIDORES VULNERABLES EN EL SECTOR ELÉCTRICO, LUCHA CONTRA LA POBREZA ENERGÉTICA Y EL BONO SOCIAL
}

\author{
ÍÑIGO DEL GUAYO CASTIELLA ${ }^{1}$ \\ Universidad de Almería \\ iguayo@ual.es
}

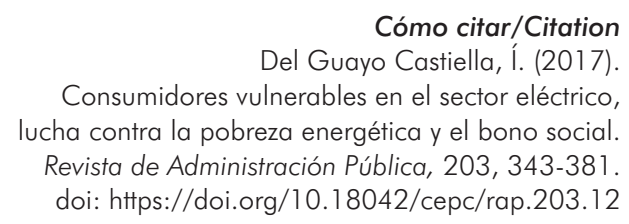

\section{Resumen}

La Unión Europea ha incorporado a las normas propias del mercado interior de la electricidad, la preocupación por afrontar la pobreza energética. En el caso espańol, ante el creciente número de consumidores que no pueden pagar la factura mensual del suministro de electricidad, el legislador ideó el bono social, en apoyo de los consumidores vulnerables. Si bien las normas mantienen la posibilidad de cortar el suministro por impago, en fechas recientes se ha procedido a incorporar dentro de los suministros esenciales a algunos consumidores individuales, cuyo suministro no puede ser cortado ni siquiera en caso de impago. Las comunidades autónomas deberían afrontar esta situación con medidas sociales y no tanto mediante el intento de modificar el régimen jurídico básico del corte por impago.

\section{Palabras clave}

Bono social; clientes vulnerables; pobreza energética; electricidad.

1 Catedrático de Derecho Administrativo. Departamento de Derecho de la Universidad de Almería. Este trabajo se terminó el 3 de mayo de 2017. 


\begin{abstract}
The European Union has introduced within the set of laws related to the Electricity Internal Market, the need of fighting energy poverty. In Spain, due to the increasing number of consumers unable to pay their monthly electricity bills, Parliament created a social bonus, as a mean of helping vulnerable consumers. Even though Spanish electricity legislation has kept unchanged the legal framework for the interruption of supply when the customer doesn't pay the bill, recent reforms have included within the list of essential supplies some individual consumers, whose supply can't be interrupted even when bills aren't settled. Autonomous Communities should address this situation by means of social aids to consumers, rather than by an attempt to change basic state law related to interruption based on the lack of payment.
\end{abstract}

\title{
Keywords
}

Social bonus; vulnerable consumers; energy poverty; electricity. 


\section{SUMARIO}

I. PLANTEAMIENTO. II. LA PROTECCIÓN DE LOS CONSUMIDORES DE ELECTRICIDAD Y LA LUCHA CONTRA LA POBREZA ENERGÉTICA EN LA UNIÓN EURO-

PEA: 1. Grupo normativo. 2. El servicio universal y el suministrador del último recurso. 3. Los clientes vulnerables y la pobreza energética. III. LA PROTECCIÓN DE LOS CONSUMIDORES VULNERABLES DE ELECTRICIDAD Y EL BONO SOCIAL EN ESPAÑA: 1. Introducción. 2. Los precios voluntarios para el pequeño consumidor, la tarifa de último recurso y el bono social. Una advertencia importante. 3. Antecedentes del bono social: 3.1. Régimen jurídico originario del bono social en 2009 y su anulación en 2012 por el Tribunal Supremo. 3.2. El régimen originario del bono social en la Ley del Sector Eléctrico de 2013 y su desarticulación por el Tribunal Supremo en 2016. 4. Régimen vigente del bono social, desde diciembre de 2016: 4.1. Concepto de consumidor vulnerable. 4.2. Determinación del bono social. 4.3. El bono social como obligación de servicio público. 4.4. Otras medidas de protección del consumidor vulnerable. 4.5. Algunas cuestiones procedimentales relativas al bono social. IV. EL CORTE DE SUMINISTRO DE ENERGÍA ELÉCTRICA Y LA FINANCIACIÓN DE UNA NUEVA OBLIGACIÓN DE SERVICIO PÚBLICO: 1. EI corte de suministro por impago. 2. El corte del suministro para consumidores con potencia instalada contratada igual o inferior a $10 \mathrm{~kW}$. 3. El corte de suministro a los consumidores vulnerables acogidos al bono social. 4. La prohibición de corte del suministro a los servicios esenciales. La creación de una nueva obligación de servicio público en 2016 y su financiación. 5. Carácter básico de los criterios de la esencialidad del suministro. V. EL CONFLICTO ENTRE EL ESTADO Y LA GENERALITAT DE CATALUÑA EN MATERIA DE PROTECCIÓN DE LOS CLIENTES VULNERABLES Y LA LUCHA CONTRA LA POBREZA ENERGÉTICA: 1. Constitución, consumidores, Estado y comunidades autónomas. 2. El conflicto entre el Estado y la Comunidad Autónoma de Cataluña, a propósito de la defensa de los consumidores vulnerables y la lucha contra la pobreza energética: 2. 1. Modificación en 2013 del Código de Consumo de Cataluña. 2.2. La Ley 20/2014, de 29 de diciembre, del Parlamento catalán. 2.3. La Sentencia 62/2016, del Tribunal Constitucional, de inconstitucionalidad de la reforma llevada a cabo por el Decreto Ley 6/2013. 2.4. El art. 6 de la Ley 24/2015, de 29 de julio, de medidas para afrontar la emergencia en el ámbito de la vivienda y la pobreza energética. 2.5. El concurso para el suministro eléctrico en el Ayuntamiento de Barcelona. VI. CONCLUSIONES. 


\section{PLANTEAMIENTO}

La defensa o protección de los consumidores constituye una política pública esencial en nuestra sociedad. Ocupa un lugar relevante en el Tratado de Funcionamiento de la Unión Europea (en adelante, $\mathrm{TFUE}^{2}$ ), y también en la Constitución española (en adelante, $\mathrm{CE}^{3}$ ). Parecería que la protección de los consumidores de energía eléctrica habría de ser considerada como una especialidad de la protección genérica de los consumidores, pero realmente constituye una parte principal del sistema eléctrico. De aquí deriva que la protección de los consumidores de electricidad goce de características que la singularizan frente al derecho ordinario de consumo.

En el sector eléctrico, las redes de transporte y distribución de electricidad son monopolios naturales por definición y la competencia en el mercado de producción y suministro ha de ser constantemente promovida, frente a la tendencia al oligopolio. Dada la presencia de monopolios y oligopolios en el ámbito de la electricidad, los consumidores deben ser protegidos. La promoción y defensa de la competencia en el mercado eléctrico corresponde al Gobierno, a la autoridad de competencia y al regulador eléctrico.

Dadas las características de las empresas que operan en el sistema eléctrico, es lógico que las leyes contengan un conjunto de medidas para proteger a los consumidores. Junto a previsiones dirigidas a proteger a todos los consumidores de electricidad, existen otras que benefician solo a un grupo: los consumidores vulnerables o aquellos que padecen la pobreza energética, a favor de los cuales existen medidas adicionales de protección, como el bono social. Este trabajo está dedicado a la protección de este grupo de consumidores. En las circunstancias actuales de crisis económica y de aumento de la pobreza, también en los países del llamado primer mundo, resulta necesario idear instrumentos para luchar contra esa situación $n^{4}$. Desde un punto de vista cuantitativo, aquellas previsiones extraordinarias ya no lo son tanto.

2 DOUE C 326, de 26 de octubre de 2012. Arts. 4, 2; 12; 114 y 169, 1, del TFUE. Existe una Carta de los Derechos Fundamentales de la UE que fue proclamada en Estrasburgo el 12 de diciembre de 2007 por el Parlamento Europeo, el Consejo y la Comisión (DOUE C 364, de 18 de diciembre de 2000). El art. 38 establece que en las políticas de la Unión se garantizará un nivel elevado de protección de los consumidores. La norma principal de derecho derivado es la Directiva 2011/83/UE del Parlamento Europeo y del Consejo, de 25 de octubre de 2011, sobre los derechos de los consumidores (DOUE L 304, de 22 de noviembre de 2011) $B O E, 311$, de 29 de diciembre de 1978. Art. 51.

4 F. J. Sanz Larruga (2016), «Función social de la Administración. Servicios de atención a necesidades básicas. Derecho de acceso a la energía y la lucha contra la pobreza ener- 


\section{LA PROTECCIÓN DE LOS CONSUMIDORES DE ELECTRICIDAD Y LA LUCHA CONTRA LA POBREZA ENERGÉTICA EN LA UNIÓN EUROPEA}

\section{GRUPO NORMATIVO}

Específicamente sobre el mercado interior de la electricidad, está en vigor hoy la Directiva 2009/72/CE del Parlamento Europeo y del Consejo, de 13 de julio de 2009 sobre normas comunes para el mercado interior de la electricidad y por la que se deroga la Directiva 2003/54/CE (en adelante, $\mathrm{DE})^{5}$. De acuerdo con el art. 3, 7 de la DE, los Estados miembros tienen la obligación de garantizar un nivel elevado de protección del consumidor, sobre todo en lo que se refiere a la transparencia de las condiciones contractuales, la información general y los procedimientos de resolución de conflictos (por lo que respecta a los clientes domésticos, estas medidas deben incluir las que se enuncian en el Anexo I de la Directiva).

\section{EL SERVICIO UNIVERSAL Y EL SUMINISTRADOR DEL ÚLTIMO RECURSO}

Dado el carácter esencial de la electricidad, el art. 3, 3, de la DE dispone que los Estados miembros deben garantizar que todos los clientes domésticos y, cuando los Estados miembros lo consideren adecuado, las pequeñas empresas (las empresas que empleen a menos de 50 personas y cuyo volumen de negocios o balance general anual no exceda de 10 millones de euros) disfruten en su territorio del derecho a un servicio universal, definido como el derecho al suministro de electricidad de una calidad determinada, y a unos precios razonables, fácil y claramente comparables, transparentes y no discriminatorios ${ }^{6}$. De acuerdo con el art. 3, 7 de la DE, los Estados miembros tienen la obligación de adoptar las medidas necesarias para proteger a los clientes eléctricos finales de zonas apartadas, incluso aunque no estén conectados a la red, lo cual significa que el Estado miembro debe garantizar que todo potencial consumidor

gética», en J. Rodríguez-Arana, C. Delpiazzo Rodríguez, W. Zambrano Cetina y M. del C. Rodríguez Martín-Retortillo, Función Social de la Administración, tomo I (págs. 527-547), Bogotá: Ibáńez/Universidad del Rosario.

5 DOUE L 211, de 14 de agosto de 2009.

6 T. de la Cuadra Salcedo (2010), «El suministro de electricidad de último recurso y el servicio universal», Revista de Administración Pública, 181, págs. 39-82; y M. Swora, N. Buchowska y A. Skoczlas (2015), «La garantía de acceso a la energía de los consumidores vulnerables», Revista Europea de derechos fundamentales, 25, págs. 223-255. 
queda conectado a la red. El servicio universal comprende la obligación de las empresas distribuidoras de conectar a los clientes a su red con arreglo a las condiciones y tarifas establecidas de conformidad con el procedimiento previsto en la propia DE (concretamente, en el art. 37, 6). El mismo art. 3, 3, de la DE contempla la posibilidad de que los Estados miembros designen un suministrador de último recurso. En el caso de la DE, esa posibilidad se establece para garantizar la prestación del servicio universal.

\section{LOS CLIENTES VULNERABLES Y LA POBREZA ENERGÉTICA}

El art. 3, 7, de la DE, dispone que los Estados miembros deben adoptar las medidas oportunas para proteger a los clientes finales y, en particular, para garantizar una protección adecuada de los clientes vulnerables. Cada uno de los Estados miembros debe definir el concepto de cliente vulnerable que puede referirse a la pobreza energética y, entre otras cosas, a la prohibición de desconexión de estos clientes en períodos críticos.

Aun cuando el derecho de la UE parece distinguir entre la lucha contra la pobreza energética y la protección de los clientes vulnerables, en realidad se trata de conceptos difícilmente separables. En la DE, ambos conceptos van normalmente juntos 7 . Según la Asociación de Ciencias Ambientales, la pobreza energética es la incapacidad de un hogar de satisfacer una cantidad mínima de servicios de la energía para sus necesidades básicas, como mantener la vivienda en unas condiciones de climatización adecuadas para la salud (de 18 a 21 grados en invierno y 25 en verano, según los criterios de la Organización Mundial de la Salud) ${ }^{8}$. No obstante, la pobreza energética es algo más amplio que la vulnerabilidad de algunos clientes de electricidad. Así como un cliente vulnerable está en situación de pobreza energética, también lo está un cliente cuyo consumo es ineficiente y por esa razón su consumo es más caro de lo normal. La ineficiencia energética podría ser entendida, desde esta perspectiva, como la auténtica pobreza energética. En algunos textos de la Unión Europea la vulnerabilidad es una condición de todos los consumidores de electricidad: así en el punto 9 de la Carta Europea de los Derechos de los Consumidores de Energía Eléctrica se afirma que la existencia de monopolios en el sector eléctrico limita la libertad de elección y las posibilidades de cambio de suministrador, agrava la falta de información y "por lo tanto, agudiza

7 Por ejemplo, considerando 53. Desde una perspectiva británica, véase C. Graham (2017), «Ofgem, Reforming Regulation and Vulnerability», Utilities Law Review, 21, págs. $1-5$.

8 http://www.cienciasambientales.org.es. 
la vulnerabilidad de los consumidores». En los considerandos de la DE se aclara que las medidas de protección a favor de los clientes vulnerables pueden diferir en función de las circunstancias concretas de cada Estado miembro, y pueden incluir medidas específicas relacionadas con el pago de las facturas de electricidad o medidas más generales adoptadas dentro del sistema de seguridad social ${ }^{9}$. Por tanto, la DE no establece qué medidas concretas debe adoptar cada Estado miembro para proteger a los clientes vulnerables, sino que señala formas, que los Estados miembros podrán adoptar o no. Concretamente, la DE no impone que la protección de los clientes vulnerables tenga que consistir en la prohibición de desconexión en períodos críticos ${ }^{10}$.

El art. 3, 8, de la DE dispone que los Estados miembros deben adoptar las medidas adecuadas, tales como planes nacionales de acción en materia de energía, prestaciones en el marco de regímenes de seguridad social para garantizar el necesario suministro de electricidad a los clientes vulnerables o el apoyo a mejoras de eficiencia energética, con el fin de atajar la pobreza energética donde se haya constatado, también en el contexto más amplio de la pobreza en general. Estas medidas no deben impedir la apertura efectiva del mercado ni su funcionamiento (art. 33 de la DE). Como se trata de medidas adoptadas para cumplir con las obligaciones de servicio público, se han de notificar esas medidas a la Comisión, cuando proceda, de conformidad con lo dispuesto en el apdo. 15 del art. 3 de la DE. En la notificación se pueden incluir también medidas adoptadas dentro del régimen general de seguridad social ${ }^{11}$.

\section{LA PROTECCIÓN DE LOS CONSUMIDORES VULNERABLES DE ELECTRICIDAD Y EL BONO SOCIAL EN ESPAÑA}

\section{INTRODUCCIÓN}

Una de las principales formas de protección del consumidor eléctrico en España ha consistido tradicionalmente en la existencia de una tarifa eléctrica

9 Considerando 45.

10 En contra, véase I. González Ríos (2013), «La protección del consumidor eléctrico y la lucha contra la pobreza energética: previsiones comunitarias e insuficiente regulación interna española», Revista de Derecho Comunitario Europeo, 45, págs. 577-605.

11 H. Thomson y C. Snell (2013), «Quantifying the Prevalence of Fuel Poverty across the European Union», Energy Policy 52, págs. 563-572; y H. Vedder, M. Roggenkamp, A. Ronne e I. del Guayo (2016), «UE Energy Law», en M. Roggenkamp, C. Redgwell, A. Ronne e I. del Guayo (eds.), Energy Law in Europe. National, EU and International Regulation, Oxford: Oxford University Press, 3a ed., párrafos 4.209-4.212. 
gubernamentalmente aprobada, que puede considerarse como un precio intervenido, con objeto de que las empresas eléctricas no cobren precios excesivos. Esa práctica ha sido realmente un potente instrumento de lucha contra la inflación, de manera que el carácter protector del consumidor se ha diluido. Una tarifa mal diseñada conllevó la aparición en España de un enorme déficit eléctrico (el llamado déficit tarifario), por cuanto esa tarifa no era suficiente para cubrir todos los costes de producción, transporte y distribución, incluyendo los costes de financiación de la producción de electricidad mediante energías alternativas y cogeneración. La necesidad de combatir ese déficit ha presidido la política eléctrica española en los últimos quince años ${ }^{12}$. La tarifa fue igualmente un instrumento para trasladar a los consumidores diversas cargas regulatorias (como la financiación de las energías renovables o la moratoria nuclear).

\section{LOS PRECIOS VOLUNTARIOS PARA EL PEQUEÑO CONSUMIDOR, LA TARIFA DE ÚLTIMO RECURSO Y EL BONO SOCIAL. UNA ADVERTENCIA IMPORTANTE}

Para la protección de los pequeños consumidores (domésticos o comerciales), la Ley 24/2013, de 26 de diciembre, del Sector Eléctrico ${ }^{13}$ (en adelante, LSE) regula unos llamados precios voluntarios para el pequeño consumidor, una tarifa de último recurso y un bono social. Los precios voluntarios para el pequeño consumidor son únicos en todo el territorio español, y son los precios máximos que pueden cobrar los comercializadores de referencia a aquellos consumidores que, de acuerdo con la normativa vigente en cada momento, cumplan los requisitos para que les resulten de aplicación. Estos precios se han de fijar de forma que en su cálculo se respete el principio de suficiencia de ingresos, aditividad y no ocasionen distorsiones de la competencia en el mercado. En síntesis, se trata de los precios que pagan los hogares y los comercios españoles (art. 17, 2, de la LSE).

Junto a la creación de un sistema de protección de todos los consumidores pequeños de electricidad, el derecho español creó la figura del consumidor no solo pequeño sino, además, vulnerable. Para proteger a esos clientes el

12 Mediante dos sentencias del TS de 18 de noviembre de 2013, el Tribunal Supremo declaró que el sistema de financiación del déficit tarifario contenido en la DA $21^{\text {a }}$ de la LSE, en relación con la DT 1a del Real Decreto-ley 6/2009 (que imponía a ciertas empresas del sector eléctrico que lo financiasen) no era contrario al art. 14 de la Constitución.

13 BOE, 310, de 27 de diciembre de 2013. 
art. 17 de la LSE diseńa una tarifa de último recurso (TUR) y un bono social. Las tarifas de último recurso son aquellos precios que pueden cobrar los comercializadores que asumen las obligaciones de suministro de referencia a los consumidores que tengan la condición de vulnerables, y a aquellos que, sin cumplir los requisitos para la aplicación del precio voluntario para el pequeño consumidor (o $p v p c$ ), transitoriamente no dispongan de un contrato de suministro en vigor con un comercializador en mercado libre. Las tarifas de último recurso son únicas en todo el territorio nacional y en su fijación se pueden incorporar descuentos o recargos sobre los precios voluntarios para el pequeńo consumidor, según se determine para cada categoría de consumidores. La TUR es fijada por el ministro de Energía, Turismo y Agenda Digital, previo acuerdo de la Comisión Delegada del Gobierno para Asuntos Económicos. A favor de los consumidores vulnerables, el art. 45 de la LSE diseńa igualmente un bono social ${ }^{14}$.

La LSE adolece de un grave defecto en punto a la determinación de qué es la tarifa de último recurso en relación con el bono social. La confusión terminológica puede fácilmente inducir a confusión conceptual. Parece, en principio, que la TUR y el bono social son cosas distintas. El art. 17 de la LSE versa sobre la tarifa de último recurso y el art. 45 de la LSE habla del bono social. Tanto la tarifa de último recurso como el bono social son beneficios que se establecen a favor de los consumidores vulnerables, de todos los consumidores vulnerables. Sin embargo, y a pesar de estar regulados en dos artículos diferentes, y a pesar de recibir dos denominaciones distintas, en realidad la tarifa de último recurso está indisolublemente unida al bono social. El art. 45 de la LSE lo dice de modo confuso, pero el art. 16, 3 del Real Decreto 216/2014, de 28 de marzo, por el que se establece la metodología de cálculo de los precios voluntarios para el pequeño consumidor de energía eléctrica y su régimen jurídico de contratación ${ }^{15}$, lo expresa un poco más claramente: «El bono social aplicado al consumidor vulnerable será la diferencia que resulte entre la facturación correspondiente al precio voluntario para el pequeño consumidor y la facturación a tarifa de último recurso».

14 Véase, en general, M. Silva Ardanuy (2014), La pobreza energética en España, Cizur Menor: Aranzadi. Una interesante visión de cómo el fomento de las renovables puede contribuir a aliviar la pobreza energética, en G. Sáez de Miera (2007), «Pobreza, brecha energética y energías renovables», Cuadernos de Energía, págs. 78-82.

$B O E, 77$, de 29 de marzo de 2014. 


\section{ANTECEDENTES DEL BONO SOCIAL}

\subsection{Régimen jurídico originario del bono social en 2009 y su anulación en 2012 por el Tribunal Supremo}

La creación de un bono social a favor de clientes vulnerables tuvo lugar mediante el Real Decreto Ley 6/2009, de 30 de abril, por el que se adoptan determinadas medidas en el sector energético y se aprueba el bono social ${ }^{16}$. Fue desarrollado por la Orden ITC/1723/2009, de 20 de junio, por la que se revisan los peajes de acceso a partir de 1 de julio de 2009 y las tarifas y primas de determinadas instalaciones de régimen especial ${ }^{17}$.

La Orden fue impugnada ante la jurisdicción contencioso-administrativa y, de modo indirecto, también el Real Decreto Ley 6/2009. Mediante STS de 7 de febrero de 2012, la Sala Tercera del Tribunal Supremo declaró inaplicable la parte del Real Decreto Ley 6/2009 relativa a las empresas que deben financiar el bono social (art. 2, 5 y DT 2a, último párrafo; en consecuencia, también se declararon inaplicables las DDAA $2^{\text {a }}$ y $3^{\text {a }}$ de la Orden ITC/1723/2009) ${ }^{18}$. La STS reconoció el derecho de la recurrente (la empresa Iberdrola) a que le fueran reintegradas las cantidades que hubiese abonado en concepto de financiación del bono social. El TS consideró que el bono social encontraba amparo en la Directiva eléctrica de 2003, pero alguno de sus requisitos no fueron respetados. El mecanismo de financiación del bono social supone una obligación discriminatoria, puesto que se carga solo sobre unas empresas concretas de un sector (generación de energía eléctrica), sin que se explicite la razón por la que deba imponerse a tales empresas la prestación patrimonial que implica la financiación del bono social. La imposición de la carga de financiación del bono social a una lista nominativa de empresas en la DT 2a del Real Decreto-ley 6/2009, carece de transparencia. Al no fijar el criterio por el cual están unas empresas, y otras no, ni especificar en virtud de qué parámetros precisos se atribuye el porcentaje de financiación concreto a cada una de las empresas afectadas, se impide verificar y controlar a cada una de ellas la exactitud o corrección de tales porcentajes y, en todo caso, se les discrimina respecto a las no incluidas en el listado. No resulta controlable por la jurisdicción contencioso-administrativa.

16 BOE, 111, de 7 de mayo de 2009.

17 BOE, 156, de 29 de junio de 2009 (corrección de errores en BOE, 167 de 11 de julio de 2009). Mediante resolución de 26 de junio de 2009, de la Secretaría de Estado de Energía, se determinó el procedimiento de puesta en marcha del bono social (BOE, 156, de 29 de junio de 2009).

18 BOE, 74, de 27 de marzo de 2012. 
El Real Decreto Ley 13/2012, de 30 de marzo, por el que se transponen directivas en materia de mercados interiores de electricidad y gas y en materia de comunicaciones electrónicas, y por el que se adoptan medidas para la corrección de las desviaciones por desajustes entre los costes e ingresos de los sectores eléctrico y gasista ${ }^{19}$, introdujo en la LSE la referencia al consumidor vulnerable (art. 44, 4): es aquel que cumpla las características sociales, de consumo y poder adquisitivo que se determinen. El mismo Real Decreto Ley introdujo en la LSE una DT $20^{\mathrm{a}}$ que dispuso que, transitoriamente, mientras no se definiese el concepto de consumidor vulnerable (en desarrollo del art. 44, 4, de la LSE), habrían de considerarse como tales a aquellos que se encontrasen dentro del ámbito de aplicación del art. 2 y de la DT 2a del Real Decreto Ley 6/2009 (es decir, los consumidores que tienen derecho a acogerse al bono social), así como en la DA 2a de Real Decreto Ley 14/2010, de 23 de diciembre, por el que se establecen medidas urgentes para la corrección del déficit tarifario del sector eléctrico. Esa DA 2a se refería al mecanismo transitorio de financiación del bono social.

\subsection{El régimen originario del bono social en la Ley del Sector Eléctrico de 2013 y su desarticulación por el Tribunal Supremo en 2016}

El art. 45 de la LSE de 2013 vino a recoger en sus líneas generales las previsiones creadas entre 2009 y 2012 sobre los consumidores vulnerables y el bono social. Varios meses después sus previsiones se desarrollaron mediante el Real Decreto 968/2014, de 21 de noviembre, por el que se desarrolla la metodología para la fijación de los porcentajes de reparto de las cantidades a financiar relativas al bono social ${ }^{20}$. En la versión original de la LSE, el bono social era el mismo para todos los consumidores con derecho a acogerse a él y el bono social debía ser asumido por las matrices de los grupos de sociedades o, en su caso, sociedades que desarrollasen simultáneamente las actividades de producción, distribución y comercialización de energía eléctrica.

Mediante cuatro sentencias de 24 de octubre de 2016 (dos de ellas son de esta misma fecha), 25 de octubre de 2016 y 2 de noviembre de 2016, la Sala de lo Contencioso-Administrativo (Sección Tercera) del Tribunal Supremo declaró que el art. 45, 4 de la LSE, que establece el bono social, es inaplicable porque es incompatible con la DE, que los arts. 2 y 3 del Real Decreto 968/2014, de 21 de noviembre, aprobado en desarrollo del art. 45, 4, de la LSE, son inaplicables y nulos, y que los demandantes (Endesa, E.On, Iberdrola

$19 B O E, 78$, de 31 de marzo de 2012.

$20 B O E, 283$, de 22 de noviembre de 2014. 
y Gas Natural Fenosa) tienen derecho a ser indemnizados por todas las cantidades abonadas en concepto de bono social, en aplicación del Real Decreto 968/2014, hasta la fecha de ejecución de la sentencia, más los intereses desde la fecha en que se hizo el pago hasta la fecha de su reintegro. Ambas sentencias van acompañadas de un voto particular discrepante ${ }^{21}$.

Para el Tribunal Supremo, la decisión de imponer a las empresas eléctricas la financiación del bono social ha de encuadrarse entre las medidas de protección de los clientes finales socialmente vulnerables que se contemplan en la DE (apdo. 53 del Preámbulo y art. 3, apdos. 7 y 8 de la DE). En cuanto a su naturaleza jurídica, debe considerarse comprendida entre las obligaciones de servicio público (art. 3, 2, de la DE). La obligación de financiación del bono social constituye una prestación patrimonial y está sujeta a la exigencia del art. 31.3 de la Constitución (debe venir impuesta por una norma de rango de ley). Tal exigencia queda cumplida con el art. 45.4 de la LSE, en el que expresamente queda señalado que «el bono social será considerado obligación de servicio público según lo dispuesto en la DE».

El Tribunal analiza a continuación si el régimen de financiación del bono social se acomoda a la DE. Hace descansar su juicio en la STS de 7 de febrero de 2012, que anuló el sistema de bono social introducido en 2009. El Alto Tribunal considera que los requisitos de la DE no han sido respetados. El mecanismo de financiación del bono social supone una obligación discriminatoria y no transparente para las empresas generadoras, y no controlable ante la jurisdicción en sus parámetros esenciales. Es discriminatoria puesto que carga toda la financiación del bono social en las empresas de generación eléctrica, sin que se explicite por qué, en lugar de cargar la financiación sobre todos los intervinientes en el sector (generación, transporte, distribución) o a la generalidad de los usuarios, o a unos y otros o, simplemente, con cargo al presupuesto estatal, dado que en definitiva se trata de la financiación de una ayuda social. El Gobierno español puede optar porque sea el propio sector eléctrico el que se haga cargo de dicha prestación social o, incluso, una parte de dicho sector, pero resulta imprescindible que se aduzcan razones suficientes y razonables para ello, que en la versión original de la LSE de 2013 no se expresan.

Para la STS, dado que no se especifica en virtud de qué parámetros precisos se atribuye el porcentaje de financiación concreto a cada una de las empresas afectadas, se impide verificar y controlar la exactitud o corrección de tales porcentajes y, en todo caso, se les discrimina respecto a las no incluidas

21 B. Lozano (2016), «El Tribunal Supremo inaplica el sistema de financiación del bono social por incumplimiento (reiterado) del derecho de la Unión Europea», Diario La Ley, 8873. 
en el listado. La falta de transparencia estriba en que no se especifican las razones que han llevado al Gobierno español a decidir que sea el sector de la generación, el que haya de asumir la financiación del bono social, y que sean unas determinadas empresas generadoras y en porcentajes cuya razón última no puede conocerse. En consecuencia, esas decisiones y/o sus consecuencias no pueden ser debidamente controlables ante los tribunales por los sujetos afectados, lo que incumple las exigencias de la DE.

En el FD 8ª el Tribunal Supremo se extiende en explicar cómo tiene jurisdicción para declarar inaplicable una ley española que considere que es contraria al derecho europeo. La convicción acerca de esa contradicción hace innecesario el planteamiento de la cuestión prejudicial (cita aquí el Tribunal Supremo la Sentencia del Tribunal de Justicia de la Unión Europea de 7 de septiembre de $2016^{22}$ ). El Tribunal llega a la conclusión de que el régimen de financiación del bono social establecido en el art. 45.4 de la LSE debe ser declarado inaplicable por resultar incompatible con la exigencia establecida en el art. 3, 2 de la DE, que establece que las obligaciones de servicio público «deberán definirse claramente, ser transparentes, no discriminatorias y controlables, y garantizar a las empresas eléctricas de la Comunidad el acceso, en igualdad de condiciones, a los consumidores nacionales». Declara inaplicable también el precepto regulador de financiación del bono social por vulnerar el principio de proporcionalidad, en cuanto hace recaer la carga de financiación sobre determinados agentes del sistema eléctrico, con exclusión de otros, de manera indefinida y sin ningún tipo de medida compensatoria.

\section{RÉGIMEN VIGENTE DEL BONO SOCIAL, DESDE DICIEMBRE DE 2016}

Tras las sentencias recaídas en 2016, que declararon inaplicable el art. 45 de la LSE y anularon los dos preceptos sustanciales del Real Decreto 968/2014, el Gobierno español promovió una reforma del sistema del bono social, por medio del Real Decreto Ley 7/2016, de 23 de diciembre, por el que se regula el mecanismo de financiación del coste del bono social y otras medidas de protección al consumidor vulnerable de energía eléctrica ${ }^{23}$.

Al Gobierno español corresponde establecer por vía reglamentaria las medidas a adoptar a favor de estos consumidores vulnerables. La reforma de 2016 reforzó la potestad gubernamental para delimitar las personas que deben ser

22 Sentencia del Tribunal de Justicia (Sala Quinta) de 7 de septiembre de 2016: Association nationale des opérateurs détaillants en énergie (ANODE) v. Premier ministre y otros (asunto C-121/15: ECLI: EU: C:2016: 637).

23 BOE, 310, de 24 de diciembre de 2016. 
protegidas, pues tras su aprobación corresponde al Gobierno no solo la definición de quién es un consumidor vulnerable, sino también qué categorías de clientes vulnerables existen (nueva redacción del segundo párrafo del art. 45, 1, de la LSE). Existe un borrador de Real Decreto que desarrolla las previsiones del Real Decreto Ley de 2016 y que el 3 de mayo de 2017 fue remitido por el Gobierno, para informe, a la Comisión Nacional de los Mercados y la Competencia. Se trata del Proyecto de Real Decreto por el que se regula el consumidor vulnerable de energía eléctrica, el bono social y las condiciones de suspensión del suministro para consumidores con potencia contratada igual o inferior a 10 $\mathrm{kW}$ (en adelante, será referido como el borrador del Real Decreto).

De acuerdo con el art. 45 de la LSE, el principal beneficio de los consumidores vulnerables es que tienen derecho a disfrutar de un bono social, que implica una sustancial rebaja de la factura eléctrica. Salvo que se trate de un consumidor vulnerable severo y en riesgo de exclusión social, la condición de consumidor vulnerable no supone que esté prohibido cortarle el suministro (en caso de impago).

\subsection{Concepto de consumidor vulnerable}

El art. 45 de la LSE se refiere hoy a los consumidores vulnerables: son aquellos consumidores de electricidad que cumplan con las características sociales, de consumo y poder adquisitivo que se determinen, por el Gobierno. A estos efectos, se establece un umbral referenciado a un indicador de renta per cápita familiar. Desde que se introdujo el concepto de consumidor vulnerable en el derecho español, se había venido reclamando que se ligase a la renta ${ }^{24}$. En todo caso, se circunscribe a personas físicas en su vivienda habitual.

A falta de la aprobación del proyecto de Real Decreto, la DT 10a de la LSE (con el encabezamiento "consumidor vulnerable y bono social»), dispone que hasta que se desarrolle lo previsto en el art. 45,1 de la LSE tienen derecho al bono social los siguientes consumidores (que han de reputarse como vulnerables):

a) aquellas personas físicas cuyo suministro se corresponda con una potencia contratada inferior a $3 \mathrm{~kW}$ en su vivienda habitual;

b) los consumidores con 60 o más años de edad que acrediten ser pensionistas del Sistema de la Seguridad Social por jubilación, incapacidad

24 E. Jaio Gabiola, J. D. Paredes Gázquez y J. A. Sánchez Rodríguez (2016), «El bono social y las cooperativas energéticas verdes: situación y perspectivas", Revista de Estudios cooperativos, 122, págs. 165-190. 
permanente y viudedad y que perciban las cuantías mínimas vigentes en cada momento para dichas clases de pensión con respecto a los titulares con cónyuge a cargo o a los titulares sin cónyuge que viven en una unidad económica unipersonal, así como los beneficiarios de pensiones del extinguido Seguro Obligatorio de Vejez e Invalidez y de pensiones no contributivas de jubilación e invalidez mayores de 60 años;

c) los consumidores que acrediten ser familias numerosas; $y$

d) los consumidores que acrediten formar parte de una unidad familiar que tenga todos sus miembros en situación de desempleo.

De acuerdo con el borrador del Real Decreto, tiene la consideración de consumidor vulnerable el titular de un punto de suministro de electricidad en su vivienda habitual que, siendo persona física, esté acogido al precio voluntario para el pequeño consumidor y acredite formar parte de una unidad familiar que cumpla determinados requisitos. Es unidad familiar la constituida conforme a lo dispuesto en la Ley 35/2006, de 28 de noviembre, del Impuesto sobre la Renta de las Personas Físicas y de modificación parcial de las leyes de los Impuestos sobre Sociedades, sobre la Renta de no Residentes y sobre el Patrimonio $^{25}$ (art. 3, apdo. 1).

La unidad familiar a la que pertenezca el consumidor debe cumplir alguno de los requisitos siguientes: a) percibir una renta anual menor o igual a 1,5 veces el Indicador Público de Renta de Efectos Múltiples (IPREM), en el caso en que no haya ningún menor en la unidad familiar ${ }^{26}$; b) percibir una renta anual menor o igual a 2 veces el IPREM en el caso de que haya un menor en la unidad familiar; c) percibir una renta anual menor o igual a 2,5 veces el IPREM en el caso de que haya dos menores en la unidad familiar; d) estar en disposición del título de familia numerosa; o e) que todos los miembros que tengan ingresos en la unidad familiar sean pensionistas del Sistema de la Seguridad Social por jubilación o incapacidad permanente, percibiendo por ello la cuantía mínima vigente en cada momento para dichas clases de pensión (art. 3, apdo. 2).

Al consumidor de energía eléctrica que acredite pertenecer a una unidad familiar especial, el porcentaje de renta respecto del IPREM establecido

25 BOE, 285, de 29 de noviembre de 2006.

26 El IPREM fue introducido por el Real Decreto Ley 3/2004, de 25 de junio, para la racionalización de la regulación del salario mínimo interprofesional y para el incremento de su cuantía (BOE, 154, de 26 de junio de 2004). Es el índice de referencia para la asignación de ayudas, en función de los ingresos. En este ámbito de las ayudas y subsidios, vino a sustituir al Salario Mínimo Interprofesional. 
en los casos a) a c) del apdo. 2 del art. 3, se incrementa en 0,5. Para que se considere que es una unidad familiar especial se ha de encontrar en alguno de los siguientes tres casos: a) que alguno de los miembros de la unidad familiar tenga discapacidad reconocida igual o superior al 33\%; b) que alguno de los miembros de la unidad familiar tenga la condición legal de víctima de violencia de género; o c) que alguno de los miembros de la unidad familiar tenga la condición legal de víctima de terrorismo (art. 3, apdo. 3).

Es consumidor vulnerable severo el consumidor de energía eléctrica que, cumpliendo los requisitos exigidos para ser vulnerable, además pertenezca a una unidad familiar que perciba una de las dos clases siguiente de renta: o bien una renta anual igual o inferior al 50\% de los umbrales establecidos en los casos a), b) o c) señalados en el apdo. 2 del art. 3 (incrementados en su caso conforme a lo dispuesto sobre unidades familiares especiales en el apdo. 3 del art. 3), o bien una renta anual menor o igual a una y dos veces el IPREM en el caso de los colectivos recogidos en los subapartados e) y d), respectivamente, del apdo. 2 del art. 3 (art. 3, apdo. 4).

Hay una remisión a disposiciones administrativas de carácter general de rango inferior, pues establece el art. 3 que para que un consumidor sea considerado vulnerable, debe acreditar el cumplimiento de los requisitos en los términos que se establezcan por resolución de la Secretaría de Estado de Energía. Además, los umbrales y porcentajes establecidos pueden ser modificados por orden del ministro de Energía, Turismo y Agenda Digital, previo Acuerdo de la Comisión Delegada del Gobierno para Asuntos Económicos (art. 3, apdos. 5 y 6).

El art. 4 del borrador de Real Decreto se refiere la figura del consumidor en riesgo de exclusión social. Queda definido como el consumidor que reúna los requisitos para ser vulnerable severo y que sea atendido por los servicios sociales de una administración autonómica o local que financie al menos el $50 \%$ del importe de su factura. De acuerdo con ese mismo precepto, el consumidor de ese tipo que esté acogido a la TUR correspondiente, se le considera suministro esencial de acuerdo con lo previsto en el art. 52, 4, letra j, de la LSE (con el principal efecto de que no se le puede cortar el suministro, ni en caso de impago).

De la redacción dada en 2016 al art. 52, 4, letra j, de la LSE, puede deducirse que hay un único tipo de consumidor vulnerable severo, que es aquel que está acogido a la TUR que está siendo atendido, respecto del suministro eléctrico, por los servicios sociales de las administraciones públicas competentes por hallarse, en atención a su renta, en riesgo de exclusión social. Por esa razón, tiene la condición de suministro esencial. Sin embargo, surge una duda interpretativa, pues parece que el borrador de Real Decreto distingue dos tipos de consumidor vulnerable severo: el consumidor vulnerable severo, a secas, que es el que cumple los requisitos del art. 3, 3 y el consumidor vulnerable severo que, además de cumplir con los requisitos del art. 3, 3, esté en riesgo de 
exclusión social. Este subtipo de consumidor severo es el contemplado en el art. 4 del borrador. En realidad, este subtipo no está determinado por el riesgo de exclusión social, a pesar de lo que dice el encabezamiento del art. 4. El subtipo está caracterizado porque por estar en ese tipo riesgo, está siendo ayudado por la Administración a pagar la factura eléctrica. En otras palabras, aunque exista el riesgo de exclusión social, el consumidor no encajará en la subcategoría del art. 4 si no está siendo atendido por la Administración, para pagar la factura eléctrica, en al menos el $50 \%$. Este matiz es de gran relevancia, a efectos de determinar cuándo se le puede cortar el suministro a ese tipo de consumidor y cuándo no se le puede cortar. Esta distinción entre dos tipos de consumidor vulnerable severo no tiene una cobertura legal clara en la LSE.

La LSE establece que la vulnerabilidad de un consumidor ha de determinarse por el Gobierno a partir de determinadas características sociales, de consumo y de poder adquisitivo. El borrador del Real Decreto mezcla en su título tres elementos: el consumidor vulnerable, el bono social y los consumidores con potencia contratada igual o inferior a $10 \mathrm{~kW}$. No se trata de elementos correlativos, necesariamente. En la determinación de quién es vulnerable, el borrador del Real Decreto usa legítimamente esos tres criterios (por ejemplo: el ser una familia numerosa constituye una característica social, la potencia instalada constituye una característica de consumo y la renta familiar constituye una característica de poder adquisitivo). El borrador, sin embargo, debe leerse con prevención, porque la forma en que estructura la regulación es un tanto defectuosa, en tanto que algunos componentes están indebidamente mezclados. La LSE no identifica consumidor vulnerable con consumidor con potencia instalada igual o inferior a $10 \mathrm{~kW}$, pero el borrador del Real Decreto sí lleva a cabo una cierta identificación, de la siguiente manera: como define al consumidor vulnerable como aquel que esté acogido al pvpc (y que cumpla otros requisitos) y como el consumidor acogido al pvpc es aquel con una potencia instalada igual o inferior al $10 \mathrm{~kW}$, entonces parece identificar al consumidor vulnerable con consumidor con una potencia instalada igual o inferior a $10 \mathrm{~kW}$. Esta identificación provoca que el art. 2 (relativo al ámbito de aplicación) afirme que lo dispuesto en el Real Decreto es de aplicación (solo) a los consumidores de energía eléctrica con potencia contratada igual o inferior a $10 \mathrm{~kW}$ que cumplan los requisitos establecidos y a los comercializadores de referencia, asi como a los demás sujetos y agentes que participen en los mecanismos que se regulan. Es decir, el borrador del Real Decreto que se pretende aprobar para regular la situación de los consumidores vulnerables se olvida de mencionar en el precepto que determina su ámbito de aplicación a los consumidores vulnerables mismos. Este defecto deriva, insisto, de esa cierta identificación (ilegítima) entre consumidores con una potencia contratada igual o inferior a $10 \mathrm{~kW}$ y los consumidores vulnerables. 


\subsection{Determinación del bono social}

El bono social es el beneficio más característico establecido a favor del consumidor vulnerable. La TUR es aquel precio de aplicación a categorías concretas de consumidores, como los consumidores vulnerables. El bono social cubre la diferencia entre el valor del precio voluntario para el pequeño consumidor ( $p v p c$ ) y la TUR (adoptada como valor base). El bono social es aplicado por el correspondiente comercializador de referencia en las facturas de los consumidores acogidos al bono (art. 45, 3, de la LSE). Concretamente, en la facturación de aquellos usuarios acogidos a la TUR se incluye, en su caso, el importe del bono social minorando el precio voluntario para el pequeño consumidor (art. 17, 7, de la LSE). En idénticos términos, el art. 16, 3, del Real Decreto 216/2014, de 28 de marzo, establece que el bono social aplicado al consumidor vulnerable es la diferencia que resulte entre la facturación correspondiente al precio voluntario para el pequeńo consumidor y la facturación a tarifa de último recurso. El art. 6, 2, del borrador del Real Decreto define la TUR de la misma manera, pero a la inversa: la TUR es el precio resultante de descontar el bono social del $p v p c$.

En la práctica, estas determinaciones significan algo tan sencillo como que la TUR es lo mismo que el bono social. Tras la reforma de 2016 el bono social no es necesariamente el mismo para todos los consumidores, sino que puede ser distinto para cada una de las categorías de consumidores vulnerables que se fijen por el Gobierno. Concretamente, de acuerdo con el art. 6, 3 del borrador del Real Decreto la TUR de aplicación al consumidor vulnerable es el precio resultante de aplicar un descuento del $25 \%$ en todos los términos que componen el $p v p c$; en el caso del consumidor vulnerable severo, el descuento es del $40 \%$. Estos porcentajes pueden ser modificados por orden del ministro, previo acuerdo de la Comisión Delegada de Asuntos Económicos.

\subsection{El bono social como obligación de servicio público}

El bono social es considerado como obligación de servicio público según lo dispuesto en la DE y es asumido por las matrices de los grupos de sociedades o, en su caso, aquellas sociedades que desarrollen simultáneamente las actividades de producción, distribución y comercialización de energía eléctrica.

En la versión inicial de la LSE, el bono social debía ser asumido por las matrices de los grupos de sociedades o, en su caso, sociedades que desarrollasen simultáneamente las actividades de producción, distribución y comercialización de energía eléctrica. Tras la reforma de 2016, y como consecuencia de la anulación del régimen del bono social por el Tribunal Supremo, el bono social debe ser asumido por las matrices de los grupos de sociedades que desarrollan 
la actividad de comercialización de energía eléctrica, o por las propias sociedades que así lo hagan si no forman parte de ningún grupo societario.

El Preámbulo del Real Decreto Ley 7/2016 justifica que esta obligación de servicio público se imponga sobre los comercializadores, porque el bono social se encuentra estrechamente vinculado a la comercialización. La imposición de la obligación de financiación del bono social a los transportistas y/o distribuidores obligaría a su necesario reconocimiento como un coste más de su actividad y, por ende, a su incorporación a la retribución regulada y a su consecuente traslación a los consumidores (incluso a los propios consumidores vulnerables beneficiados por el bono social) a través de los peajes de acceso, lo que vendría a neutralizar la finalidad perseguida con la medida. Algo parecido ocurriría para las instalaciones de producción de energía eléctrica con régimen retributivo específico, a saber, la generación a partir de fuentes de energía renovables, cogeneración y residuos con régimen primado.

El porcentaje de reparto de las cantidades a financiar se calcula para cada sociedad o grupo de sociedades de forma proporcional a la cuota de clientes a los que suministre, como la relación entre un término que será el valor medio anual de clientes que corresponda a cada uno los sujetos obligados, y otro término que corresponderá a la suma de todos los valores medios anuales de clientes del conjunto de sociedades comercializadoras. Antes de la reforma de 2016, la relación lo era entre dos términos, también, pero el primero estaba constituido por la suma de las medias anuales del número de suministros conectados a las redes de distribución de las empresas distribuidoras y del número de clientes de las empresas comercializadoras en que participe el grupo, y el otro término correspondía a la suma de todos los valores medios anuales de suministros y clientes de todos los grupos empresariales que debían ser considerados para llevar a cabo ese reparto. Como se ve, el cambio consiste fundamentalmente en la elección de los clientes suministrados como criterio exclusivo, con independencia de otros criterios, como los clientes conectados a las redes de distribución. En los grupos societarios de los que forme parte más de una comercializadora de energía eléctrica el cálculo de la cuota de clientes a los que se suministra energía eléctrica se obtiene agregando las cuotas individuales de cada una de estas.

El Real Decreto Ley 7/2016 contiene un Anexo con los porcentajes que corresponden a un total de casi trescientas comercializadoras de energía eléctrica que operan en España. Ahora bien, la mayor parte de la financiación del bono social recae sobre los cinco grandes grupos energéticos que operan en España: a) Endesa, con más del 37\%, b) Iberdrola, con más del 35\%, c) Gas Natural Fenosa, con más del 15\%, d) EDP, con casi el 4\% y e) Viesgo, con el 1,35\%.

El porcentaje de reparto es calculado anualmente por la CNMC, quien debe publicar anualmente en su página web la información, referida 
al periodo considerado, relativa a los valores medios anuales de clientes de energía eléctrica que correspondan a cada uno de los sujetos, así como la relación de sociedades o grupos de sociedades que hubiera considerado en su propuesta, determinada a partir de los datos del último año completo de que se disponga (antes de la reforma, la CNMC debía publicar la información relativa a las medias anuales del número de suministros conectados a las redes de distribución de las empresas distribuidoras y del número de clientes de las empresas comercializadoras, así como la relación de grupos de sociedades o, en su caso, sociedades que desarrollasen simultáneamente las actividades de producción, distribución y comercialización de energía eléctrica).

Dos novedades adicionales del régimen establecido en 2016 son las siguientes. Por una parte, se pueden establecer mecanismos para regularizar, en sentido positivo o negativo, las cantidades aportadas por los distintos sujetos, reconociendo, en su caso, los derechos de cobro u obligaciones de pago que correspondan, y garantizar la correcta aplicación de lo establecido sobre el bono social. En segundo lugar, el mecanismo del bono social se ha de revisar por el Gobierno al menos cada cuatro ańos para adecuarlo a la situación del sector eléctrico.

\subsection{Otras medidas de protección del consumidor vulnerable}

El proyecto de Real Decreto contiene en su art. 5 otras medidas de protección del consumidor vulnerable, en relación con el bono social. Así, cuando una comercializadora anuncie a un consumidor que está en el mercado libre, con potencia contratada igual o inferior a $10 \mathrm{~kW}$, que va a proceder a suspender su suministro, por impago, ha de comunicarle que puede acogerse al $p v p c$, así como las condiciones en las cuales podría acogerse al bono social. $\mathrm{Si}$ un consumidor acogido al $p v p c$ y con bono social, se quiere marchar al mercado libre, el comercializador debe advertirle de la pérdida del bono social. Por último, si un consumidor acogido al $p v p c$, sin bono social, se quiere marchar al mercado libre, el comercializador debe advertirle de que podría acogerse, si quiere, al bono social.

\subsection{Algunas cuestiones procedimentales relativas al bono social}

Los arts. 7 a 10 del borrador de Real Decreto se refieren, respectivamente, a la solicitud del bono social, a la comprobación de los requisitos para la aplicación del bono, a su aplicación y a su renovación. Debe destacarse el carácter voluntario con el cual se configuran los posibles convenios entre las administraciones públicas y las comercializadoras: concretamente, en materia de obtención de información de los solicitantes del bono social (art. 6, 5, en 
relación con el 7, 5, ambos del borrador del Real Decreto). Es igualmente relevante destacar que el bono social se disfruta por un ańo y que antes de que finalice el plazo el beneficiario debe volver a solicitarlo.

\section{EL CORTE DE SUMINISTRO DE ENERGÍA ELÉCTRICA Y LA FINANCIACIÓN DE UNA NUEVA OBLIGACIÓN DE SERVICIO PÚBLICO}

\section{EL CORTE DE SUMINISTRO POR IMPAGO}

En las condiciones que reglamentariamente se determinan el art. 52 de la LSE permite que pueda ser suspendido el suministro de energía eléctrica a los consumidores acogidos a precios voluntarios para el pequeño consumidor o tarifas de último recurso cuando hayan transcurrido al menos dos meses desde que les hubiera sido requerido fehacientemente el pago, sin que el mismo se hubiera hecho efectivo; a esos efectos, el requerimiento se practica por cualquier medio que permita tener constancia de la recepción por el interesado o su representante, así como de la fecha, la identidad y el contenido del mismo $^{27}$.

El Real Decreto 1955/2000, de 1 de diciembre, por el que se regulan las actividades de transporte, distribución, comercialización, suministro y procedimientos de autorización de instalaciones de energía eléctrica ${ }^{28}$, regula la suspensión del suministro por impago (título VI, sobre suministro, capítulo I, sección 4a, "pago y suspensión del suministro»: arts. 84 a 89). Se expresa en términos similares a la LSE de 2013. Además de señalar que el suministro será repuesto al día siguiente del abono de la cantidad adeudada (como establece el art. 52, 5 de la LSE) añade que la reposición depende también del abono de los intereses que se haya devengado y de la cantidad autorizada en concepto de reconexión del suministro.

Respecto de las administraciones públicas acogidas a precios voluntarios para el pequeńo consumidor o tarifas de último recurso, establece el art. 52, 3 (segundo párrafo) de la LSE que procede la interrupción del suministro si

27 Aun cuando referida a una empresa de suministro de gas, vale la referencia (pues la exigencia de notificación fehaciente es la misma en electricidad y en gas), el TS confirmó la multa impuesta a la empresa que cortó el suministro pues no constaba que se hubiese requerido de modo fehaciente al cliente: STS de 9 de marzo de 2017 (Sala Tercera).

28 BOE, 310, de 27 de diciembre de 2000. 
transcurridos cuatro meses desde el primer requerimiento, el pago no se ha hecho efectivo. Tras la reforma de 2016, este plazo más largo de cuatro meses (en comparación con los dos meses de que disponen los consumidores individuales) se puede otorgar a determinadas categorías de consumidores vulnerables, según se establezca reglamentariamente.

\section{EL CORTE DEL SUMINISTRO PARA CONSUMIDORES CON POTENCIA INSTALADA CONTRATADA IGUAL O INFERIOR A $10 \mathrm{KW}$}

Desde su aprobación original en 2013, la LSE dispuso que podía ser suspendido el suministro a los consumidores acogidos a precios voluntarios para el pequeño consumidor o tarifas de último recurso cuando hubiesen transcurrido al menos dos meses desde que les hubiera sido requerido fehacientemente el pago, sin que el mismo se hubiera hecho efectivo. Había un llamamiento a la determinación gubernamental, vía reglamento, de las condiciones en que la suspensión podía tener lugar. Pues bien, el borrador del Real Decreto contiene en su capítulo VI el procedimiento de suspensión del suministro a consumidores con potencia contratada igual o inferior a $10 \mathrm{~kW}$, que son los consumidores que, de acuerdo con el Real Decreto 216/2014, de 28 de marzo, tienen derecho a acogerse a los precios voluntarios para el pequeño consumidor (o $p v p c$ ). Conviene no olvidar que la regulación de este procedimiento, propiamente, no deriva de ningún mandato del Real Decreto Ley de 2016, sino que conecta directamente con el llamamiento que hace la LSE de 2013 a un desarrollo reglamentario. Sí constituye una novedad del Real Decreto Ley el nuevo plazo que se confiere a los consumidores vulnerables. De esto trata el epígrafe siguiente.

\section{EL CORTE DE SUMINISTRO A LOS CONSUMIDORES VULNERABLES ACOGIDOS AL BONO SOCIAL}

El art. 52, 3 de la LSE de 2013 establece que puede suspenderse el suministro de energía eléctrica a los consumidores acogidos a precios voluntarios para el pequeño consumidor o tarifas de último recurso cuando hayan transcurrido al menos dos meses desde que les haya sido requerido fehacientemente el pago, sin que el mismo se haya hecho efectivo. En el caso de las administraciones públicas acogidas a los precios voluntarios para el pequeño consumidor, el plazo de dos meses se extiende a cuatro. El Real Decreto Ley 7/2016 estableció que ese plazo de cuatro meses regiría también a favor de «las categorías de consumidores vulnerables que se determinen reglamentariamente a estos efectos». Pues bien, el proyecto de Real Decreto fija en cuatro el plazo para el pago de los consumidores vulnerables acogidos al bono social (art. 19, 4, segundo párrafo in fine). 


\section{LA PROHIBICIÓN DE CORTE DEL SUMINISTRO A LOS SERVICIOS ESENCIALES. LA CREACIÓN DE UNA NUEVA OBLIGACIÓN DE SERVICIO PÚBLICO EN 2016 Y SU FINANCIACIÓN}

Desde la versión original de la LSE se consideran suministros esenciales aquellos suministros que cumplan alguno de los criterios establecidos en el art. 52 (por ejemplo, alumbrado público, suministro de agua para el consumo humano, centros penitenciarios, transportes de servicio público, centros sanitarios y hospitales, etc.). A esa lista de nueve servicios esenciales, el Real Decreto Ley 7/2016 añadió un décimo servicio esencial. Tras la reforma de 2016, se consideran suministros esenciales, en los términos y condiciones que se establezcan reglamentariamente, también aquellos suministros a consumidores que tengan la condición de vulnerables severos acogidos a tarifas de último recurso y que estén siendo atendidos, respecto a estos suministros, por los servicios sociales de las administraciones públicas competentes por hallarse, en atención a su renta, en riesgo de exclusión social; estos suministros se circunscriben a personas físicas en su vivienda habitual, todo lo anterior debe ser acreditado mediante documento expedido por los servicios sociales de las referidas administraciones públicas (art. 52, 4, letra j, letra añadida en la reforma de 2016).

Las dos principales consecuencias derivadas a favor de un suministro considerado como esencial están establecidas en el art. 52, 4: a) «En ningún caso podrá suspenderse el suministro de energía eléctrica a aquellas instalaciones cuyos servicios hayan sido declarados como esenciales de conformidad con esta ley»; ni siquiera el impago permite que se corte el suministro a un servicio esencial; y b) las empresas distribuidoras o comercializadoras pueden aplicar recargos o afectar los pagos que perciban de aquellos de sus clientes que tengan suministros vinculados a servicios declarados como esenciales en situación de morosidad, al abono de las facturas correspondientes a dichos servicios, con independencia de la asignación que el cliente, público o privado, hubiera atribuido a estos pagos (tras la reforma de 2016, la posibilidad de establecer recargos queda prohibida respecto de los suministros esenciales relativos a los clientes vulnerables severos, mencionados en la letra j del apdo. 4 del art. 52).

El art. 20 del borrador del Real Decreto lleva por encabezamiento el siguiente: «Suspensión del suministro al consumidor en riesgo de exclusión social». Se trata de un encabezamiento que puede conducir a error, porque el precepto reitera lo que se dice en al art. 52, 4, letra j, de la LSE, es decir, que a los consumidores vulnerables severos (que el encabezamiento del art. 20 del borrador de Real Decreto llama consumidores en riesgo de exclusión social) no se les puede cortar el suministro. El precepto concreta un tanto lo previsto en el 
art. 52, 4, letra j. El suministro del consumidor vulnerable severo acogido a la correspondiente TUR, que esté siendo atendido, respecto a su suministro, por los servicios sociales de una administración autonómica o local, no podrá ser suspendido. Y concreta en qué consiste "estar atendido»: cuando los servicios sociales de la administración autonómica o local asuman al menos el $50 \%$ del importe de su factura a $p v p c$ previo a la aplicación del descuento por bono social, y el pago quede acreditado ante el comercializador de referencia en el plazo de cinco meses desde la emisión de la factura. El resumen conclusivo al que se puede llegar, tras la lectura del borrador de Real Decreto, es el siguiente: al cliente vulnerable severo se le puede cortar el suministro por impago, salvo que se encuentre en riesgo de exclusión social y, por tanto, su factura esté siendo pagada, al menos en el $50 \%$, por una Administración pública. Esto no es lo que dice, exactamente, la LSE, pero tampoco es necesariamente contrario a la LSE.

Antes de la reforma de 2016, la condición de cliente vulnerable (definido por la propia LSE) conllevaba determinados beneficios, como el disfrute de un bono social, pero no implicaba la prohibición de cortar el suministro a esos clientes, en caso de impago. La extensión de la condición de suministro esencial a algunos clientes vulnerables (severos) implica una nueva obligación de servicio público, como se ocupa de recordar el preámbulo del Real Decreto Ley 7/2016: la asunción parcial del coste que pueda derivarse del suministro de energía eléctrica al colectivo de suministros esenciales en su modalidad de clientes vulnerables severos se configura como una nueva obligación de servicio público, según lo dispuesto en la $\mathrm{DE}$. La obligación es asumida por los mismos sujetos a los que corresponde el reparto del coste del bono social (las sociedades comercializadoras o los grupos de sociedades donde se integren las comercializadoras). Las aportaciones que deban realizarse por este concepto están diferenciadas de las que correspondan al bono social. Tienen el límite máximo que se establezca mediante orden del ministro de Energía, Turismo y Agenda Digital, y previo Acuerdo de la CDGAE. Estas aportaciones tienen carácter parcial o de cofinanciación, complementando las que realicen las administraciones públicas competentes encargadas de atender a los suministros que se identifiquen en situación de riesgo de exclusión social y consumidores vulnerables severos. Hay una remisión al reglamento para el establecimiento de los mecanismos y actuaciones necesarios para la asignación de tales aportaciones (art. 45, 4, de la LSE — según la redacción que le dio el Real Decreto Ley 7/2016, en relación con el art. 52, 4, letra j, de la LSE).

El capítulo IV del borrador del Real Decreto (art. 12) lleva por encabezamiento «financiación del coste del suministro del consumidor en riesgo de exclusión social». Se trata, sin embargo, de un encabezamiento equivocado. La financiación se encuentra en el capítulo V. El mismo art. 12 remite a los arts. 14 y 15 (integrantes del capítulo V) que es donde se dice cómo se liquida 
la parte de la factura del consumidor en riesgo de exclusión social, que no es pagada por la Administración competente en materia de servicios sociales.

\section{CARÁCTER BÁSICO DE LOS CRITERIOS DE LA ESENCIALIDAD DEL SUMINISTRO}

La Generalitat de Cataluña impugnó el art. 52 de la LSE. Consideró que la regulación establecida por la LSE no dejaba margen a la Generalitat para dictar sus propias disposiciones tendentes a ampliar el catálogo de servicios considerados esenciales en su ámbito territorial. Mediante STC 32/2016, de 18 de febrero, el Tribunal desestimó el recurso. Para el TC, según su tenor y finalidad, el art. 52 de la LSE encaja con naturalidad en el concepto de bases del sector eléctrico en la medida en que se relaciona con uno de los principios que lo rige, el de garantía del suministro, que, en este caso, es absoluta.

\section{EL CONFLICTO ENTRE EL ESTADO Y LA GENERALITAT DE CATALUÑA EN MATERIA DE PROTECCIÓN DE LOS CLIENTES VULNERABLES Y LA LUCHA CONTRA LA POBREZA ENERGÉTICA}

\section{CONSTITUCIÓN, CONSUMIDORES, ESTADO Y COMUNIDADES AUTÓNOMAS}

El art. 51 de la CE se refiere a la defensa de los consumidores y usuarios. No atribuye competencias en materia de defensa de los consumidores a ninguna concreta Administración pública, sino a todas ellas. Las reglas de distribución de competencias entre el Estado y las comunidades autónomas se encuentran en los arts. 148 y 149 de la CE y en los Estatutos de Autonomía. $\mathrm{El}$ art. 51 de la CE no altera estas reglas ${ }^{29}$. La atribución de competencias constitucionales en materia de energía se encuentra en el art. 149, 1, 25 a de la CE, que atribuye al Estado la competencia exclusiva al Estado sobre las bases del régimen minero y energético; y de modo complementario, en el art. $149,1,13^{\mathrm{a}}$, de la CE, que atribuye al Estado la competencia exclusiva sobre las bases y coordinación de la planificación general de la actividad económica.

Durante el año 2016 recayeron varias sentencias sobre el sector eléctrico, alguna de las cuales abordó de modo específico la competencia del Estado para

29 M. Rebollo Puig y M. Izquierdo Carrasco (2008), "Comentario al art. 51. La intervención pública en defensa de los consumidores y usuarios», en M. L. Casas Baamonde y Rodríguez-Piñero y Bravo-Ferrer, M. (dirs.), Comentarios a la Constitución española. XXX Aniversario, Madrid: Wolters Kluwer, págs. 1136-1149. 
regular el bono social con carácter básico para toda Espańa. La STC 32/2016, de 18 de febrero, no encontró ninguna tacha de inconstitucionalidad en los preceptos impugnados de la LSE de 2013. Para el TC los aspectos relativos a la calidad del suministro constituyen un común normativo necesario para asegurar el principio de garantía del suministro de energía eléctrica a todos los consumidores, en aras del correcto funcionamiento de los diferentes sectores de la economía nacional. La STC 76/2016, de 14 de abril, reputó que la regulación del autoconsumo en la LSE no invadía las competencias de la Junta de Andalucía. La STC 62/2016, de 17 de marzo, a propósito de un recurso del Gobierno español contra el Decreto Ley catalán de 2013, recordó que la trascendencia del sector eléctrico «justifica que el Estado pueda intervenir en la ordenación del sector eléctrico tanto a través del título general relativo a la planificación general de la economía (art. 149.1.13 CE) como mediante el más específico relativo al sector energético (art. 149.1.25 CE)».

\section{EL CONFLICTO ENTRE EL ESTADO Y LA COMUNIDAD AUTÓNOMA DE CATALUÑA, A PROPÓSITO DE LA DEFENSA DE LOS CONSUMIDORES VULNERABLES Y LA LUCHA CONTRA LA POBREZA ENERGÉTICA}

\subsection{Modificación en 2013 del Código de Consumo de Cataluña}

El Decreto Ley 6/2013, de 23 de diciembre, del Gobierno catalán, modificó la Ley 22/2010, de 20 de julio, del Código de Consumo de Cataluña. Concretamente, el art. 2 del Decreto Ley añadió al art. 252-4, del Código de Consumo, los apdos. 6 a 9. En lo que aquí interesa, los apdos. 6 y 7 decían así:

6. Al recibir un aviso de interrupción del suministro de electricidad o gas las personas en situación de vulnerabilidad económica, que cumplen los requisitos establecidos en la letra v) del art. 111.2, deben presentar en el plazo máximo de diez días desde su recepción un informe de los servicios sociales básicos sobre su situación personal o, en su caso, copia de la solicitud registrada de haber solicitado su emisión.

En el caso de que no se haya presentado el informe de los servicios sociales básicos, sino únicamente su solicitud, la empresa suministradora suspenderá la interrupción del suministro hasta que éste se aporte, o transcurran dos meses desde que se le comunicó que se había solicitado.

Las Administraciones públicas responsables deben emitir este informe en el plazo máximo de quince días, desde la fecha de su solicitud. Este informe, que acreditará el cumplimiento de los requisitos previstos en la letra v) del art. 111.2, puede ser también emitido de oficio por los servicios sociales básicos, y tiene una vigencia de seis meses a partir de su emisión, sin perjuicio de su renovación. 
7. Respecto a las unidades familiares a las que se refiere la letra $v$ ) del art. 111.2 quedarán protegidas de corte de suministro entre los meses de noviembre y marzo, ambos incluidos. La deuda que se pueda acumular con las empresas suministradoras se aplazará con las condiciones que ambas partes acuerden o bien mediante los mecanismos de mediación y arbitraje que las partes acepten. Sin perjuicio de los acuerdos o del resultado de la mediación o arbitraje, el consumidor tiene, en cualquier caso, el derecho a satisfacer la deuda pendiente de manera integra o fraccionada entre los meses de abril a octubre siguientes ${ }^{30}$.

\subsection{La Ley $20 / 2014$, de 29 de diciembre, del Parlamento catalán}

El Decreto Ley 6/2013 fue convalidado por el Parlamento catalán el 22 de enero de 2014. Fue posteriormente derogado por la Ley 20/2014, de 29 de diciembre, del Código de Consumo de Cataluña, para la mejora de la protección de las personas consumidoras en materia de créditos y préstamos hipotecarios, vulnerabilidad económica y relaciones de consumo. En el art. 3 de la ley de 2014 se da una nueva definición de personas en situación de vulnerabilidad económica, para lo cual se añadió la letra w al art. 111-2 de la Ley 22/2010, del Código de Consumo. En su art. 17 se añaden cinco apdos., del 6 al 10 al art. 252-4 de la Ley 22/2010, en que se establecen deberes de información de las empresas prestadoras de servicios, así como el procedimiento aplicable en caso de impago de las personas en situación de vulnerabilidad económica, en términos similares a los establecidos en el Decreto Ley $6 / 2013^{31}$.

\subsection{La Sentencia 62/2016, del Tribunal Constitucional, de inconstitucionalidad de la reforma llevada a cabo por el Decreto Ley 6/2013}

El Gobierno español recurrió contra el Decreto Ley catalán de 2013, pues consideró que vulneraba las competencias estatales establecidas en los apdos. $13^{\text {a }}$ y $25^{\text {a }}$ del art. 149,1 , de la CE. Durante la tramitación del proceso se

30 El párrafo segundo del apdo. 6 y el apdo. 7, fueron declarados inconstitucionales por la STC 62/2016, de 17 de marzo; por esa razón los he transcrito en cursivas. Sobre el arbitraje y los consumidores vulnerables, véase M. Martínez Martínez (2016), «Contratación asimétrica de gas y electricidad con consumidores vulnerables: el bono social (aportación al debate desde la experiencia en instituciones arbitrales de consumo)», en C. Hornero Méndez, M. Espejo Lerdo De Tejada, F. Oliva Blázquez y J. P. Murga Fernández, Derecho de contratos: nuevos escenarios y nuevas propuestas, Cizur Menor: Aranzadi, págs. 383-400.

31 A. I. Mendoza Losana (2015), «Los derechos del consumidor (catalán) en situación de pobreza energética, más ruido que nueces», Revista CESCO de Derecho del Consumo, 13, págs. 62-78. 
planteó si debería entenderse extinguido el proceso tras la derogación de la norma por la Ley 20/2014, como es lo normal. Dijo el Tribunal Constitucional que esa regla tiene excepciones, como cuando el pleito tiene carácter competencial y la controversia no puede entenderse resuelta con la derogación de la norma. Esto es lo que ocurría en este caso porque, además, los preceptos derogados fueron sustituidos por otra norma que plantearía, en su caso, similares problemas de constitucionalidad. En consecuencia, el proceso no había perdido objeto.

La STC 62/2016, de 17 de marzo, reputó que el segundo párrafo del apdo. 6 y el apdo. 7, del art. 252-4, del Código de Consumo de Cataluña, en la redacción que les dio el Real Decreto Ley, son inconstitucionales y nulos. Por diversas razones de tipo procesal, el juicio del Tribunal Constitucional se contrajo a esos dos preceptos. Para el Tribunal Constitucional, la norma catalana es inconstitucional porque invade las competencias del Estado en materia de fijación de las bases del régimen minero (art. 149, 1, 25a) y fijación de las bases y coordinación de la planificación general de la actividad económica (art. 149, 1, 13a). Esa invasión se produce porque los nuevos preceptos del Código de Consumo catalán son contrarios a las bases estatales en materia de energía, tal y como quedan establecidas en las normas de la LSE.

El Tribunal Constitucional entiende que la DE confiere a los Estados miembros una libertad para determinar quiénes son clientes vulnerables y cómo van a quedar protegidos. La prohibición de desconexión en situaciones críticas de que habla la DE es una posibilidad que queda en manos de cada Estado miembro. El Estado español optó inicialmente por proteger a los Estados miembros mediante una reducción del precio de electricidad, mediante la tarifa de último recurso y el bono social (a partir del Real Decreto Ley 7/2016 se prohíbe la desconexión de los consumidores vulnerables severos). Las previsiones de la LSE (anteriores a la reforma del Real Decreto Ley 7/2016) suponen una opción por «un modelo de protección de la garantía del suministro para los consumidores vulnerables consistente en la bonificación de parte del precio, frente a otros modelos que, siendo igualmente legítimos, como la prohibición de desconexión, también pudieran garantizar el suministro a dicho colectivo» (STC 62/2016). No había en derecho español (hasta finales de 2006) una excepción al corte del suministro por impago, tal y como lo regula la LSE. La posibilidad de que una comunidad autónoma prohíba la desconexión a determinados clientes que no pagan en determinados momentos y la previsión de un aplazamiento de la deuda vulnera las competencias del Estado por vulnerar las bases estatales contenidas en la LSE (salvo, por supuesto, a los clientes vulnerables severos, figura introducida a finales de 2016).

El TC afirma que no puede plantearse ninguna objeción a la definición de cliente vulnerable contenida en la norma catalana, pero considera que es inconstitucional que a esa definición se anude un régimen jurídico-económico 
distinto para los consumidores catalanes de electricidad (como la prohibición de conexión durante algunos meses críticos del año y el aplazamiento de la deuda). Y afirma también el TC que si la Generalitat de Cataluña hubiese optado por proteger a los clientes vulnerables mediante ayudas a esos clientes para que paguen su factura, el Tribunal no hubiese encontrado ningún reproche de inconstitucionalidad, pues tal cosa no hubiese tenido una incidencia negativa en el régimen económico integrado de la electricidad y hubiese encontrado acomodo en las competencias de la Generalitat en materia de consumo.

El FJ 8 de la STC 62/2016 confronta la norma catalana que permite que se prohíba suspender el suministro en algunos casos de impago (y el consiguiente aplazamiento de la deuda con la comercializadora), con la ausencia (antes de diciembre de 2016) de toda previsión en ese sentido en las leyes estatales. En el FJ 9, la STC 62/2016 repasa las medidas adoptadas por el Estado español para la protección de los consumidores vulnerables. Para el TC, las previsiones de la LSE sobre suspensión del suministro y sobre clientes vulnerables aseguran una regulación normativa uniforme en el ámbito de la garantía del suministro de la electricidad y del gas, vigente en todo el territorio estatal, necesaria «para asegurar la unidad fundamental prevista por las normas del bloque de la constitucionalidad que establecen la distribución de competencias». Esas previsiones encajan en el concepto de bases del sector eléctrico, porque la garantía del suministro es aquí absoluta (SSTC 32/2016, de 18 de febrero).

La sentencia va acompañada de dos votos particulares, disidentes, uno suscrito por dos magistrados y otro suscrito por un magistrado en solitario. Entre otros argumentos, esos votos particulares entienden que la norma catalana impugnada debería encuadrarse en la materia de "consumo", donde la Generalitat catalana goza de mayores competencias. Incluso encuadrada en la materia "energía», esas normas estarían respaldadas por la inequívoca competencia de las comunidades autónomas para aprobar medidas adicionales en materia de calidad del suministro. Entienden los autores de los votos particulares que el Estado español no ha transpuesto adecuadamente la DE y que la Generalitat pudo legítimamente ejercer sus competencias dada la pasividad del Gobierno español. Aun cuando existiesen elementos para aceptar que, efectivamente, el Gobierno español no ha traspuesto adecuadamente la DE, ningún voto particular recuerda que, si alguna vez se produjera esa completa trasposición el derecho catalán quedaría desplazado por las nuevas bases estatales españolas. 


\subsection{El art. 6 de La Ley 24/2015, de 29 de julio, de medidas para afrontar la emergencia en el ámbito de la vivienda y la pobreza energética}

En la Comunidad Autónoma de Cataluña, uno de los principales medios para combatir la pobreza energética es el art. 6 de la Ley 24/2015, de 29 de julio, de medidas para afrontar la emergencia en el ámbito de la vivienda y la pobreza energética ${ }^{32}$. No es el único instrumento, pues subsisten algunos otros instrumentos (aquellos que no han sido declarados inconstitucionales) en el Código de Consumo de 2010.

El art. 6 de la Ley 24/2015 contiene medidas para evitar la pobreza energética. Su apdo. 2 obliga a que se establezca, como principio de precaución, un protocolo obligado de comunicación a los servicios sociales y de intervención de estos servicios previamente a la concesión de las ayudas necesarias para evitar los cortes de suministro, en los casos de impago por falta de recursos económicos de las familias afectadas. Su apdo. 3 dispone que las administraciones públicas deben establecer los acuerdos o convenios necesarios con las compañías de suministro de agua potable, de gas y de electricidad para garantizar que concedan ayudas a fondo perdido a las personas y unidades familiares en situación de riesgo de exclusión residencial o les apliquen descuentos muy notables en el coste de los consumos mínimos. De conformidad con el apdo. 4, para que se aplique el principio de precaución, cuando la empresa suministradora tenga que realizar un corte de suministro debe solicitar previamente un informe a los servicios sociales municipales para determinar si la persona o la unidad familiar se encuentra en una de las situaciones de riesgo de exclusión residencial. En el supuesto de que se cumplan estos requisitos deben garantizarse los suministros básicos y deben aplicarse las ayudas necesarias establecidas para no generar deuda alguna a la persona o la unidad familiar.

El art. 6 de la Ley 24/2015 no contiene un procedimiento para proceder a la suspensión del suministro, ni tan siquiera un trámite de ese procedimiento (como podría ser reputado el informe previo de los servicios sociales), ni podría contenerlo (pues sería inconstitucional). La finalidad del art. 6 de la

32 BOE, 216, de 9 de septiembre de 2015. Existe un recurso de inconstitucionalidad (núm. 2501-2016), interpuesto por el presidente del Gobierno español, contra los arts. 2 (apdo. 2), 3, 4, 5 (apdos. 1, 2, 3, 4 y 9), 7, la disposición adicional, la disposición transitoria segunda (apdo. primero y apdo. segundo en lo que se refiere a la aplicación del art. 7) y la disposición final tercera de la Ley del Parlamento de Cataluña 24/2015, de 29 de julio, de medidas urgentes para afrontar la emergencia en el ámbito de la vivienda y la pobreza energética; esos preceptos siguen en suspenso (BOE, 134, de 3 de junio de 2016, y 238, de 1 de octubre de 206). 
Ley 24/2015 no es la regulación de un procedimiento para la imposición de la prohibición de la interrupción del suministro. Ese es el objeto del art. 252-4 del Código de Consumo (apdos. 6 a 9, que fueron parcialmente declarados inconstitucionales en 2016 por el Tribunal Constitucional).

Dos razones principales avalan esta postura. En primer lugar, en ningún lugar de la Ley 24/2015 (ni siquiera en el preámbulo) se mencionan las directivas europeas de 2009, donde se habla de la posibilidad de suspender la interrupción del suministro. Sin embargo, tanto el Decreto Ley 6/2013 como la Ley 20/2014 (en sus respectivos preámbulos) afirman expresamente que tratan de dar cumplimiento a las previsiones de esas directivas. El preámbulo de la Ley 24/2015 menciona el Pacto Internacional de los Derechos Económicos, Sociales y Culturales (PIDESC), la Constitución española y el Estatuto de Autonomía para Cataluña ${ }^{33}$, pero no menciona ninguna norma europea. El autor de la Ley 24/2015 es consciente de que si fuese admisible que una norma catalana contuviese un procedimiento específico para prohibir la interrupción del suministro a algunos clientes (incluyendo el informe), tal norma sería el Código de Consumo. La última frase del preámbulo de la Ley 24/2015 lo dice expresamente: «los arts. 251 y 252 del Código de consumo amparan también estos derechos con relación a los suministros básicos».

En segundo lugar, la Ley 24/2015 fue aprobada el 29 de julio de 2015, ocho meses antes de que la Sentencia del Tribunal Constitucional 62/2016 estableciese que la regulación del procedimiento para la interrupción del suministro corresponde exclusivamente al Estado y declarase que el apdo. 7 y el segundo párrafo del apdo. 6, del art. 252-4 (del Código de Consumo), son inconstitucionales. Esta cronología pone de manifiesto que el art. 6 de la Ley 24/2015 no vino a desplazar ni a enmendar lo establecido en el art. 252-4 del Código de Consumo. La Ley 24/2015 se aprobó antes de que la parte del Código de Consumo relativa al procedimiento de corte por impago fuese declarada inconstitucional. Carecería de sentido que el legislador catalán diseñase entre 2013 y 2014 un procedimiento para impedir la interrupción del suministro a determinados clientes vulnerables (un procedimiento que luego fue declarado inconstitucional) y que otra ley catalana, unos meses después, en julio de 2015, viniese a alterar ese procedimiento o a reiterarlo.

La finalidad del art. 6 de la Ley 24/2015 (y también del informe a que hace referencia el apdo. 4) es identificar a las personas que, por encontrarse en riesgo de exclusión residencial, necesiten ayuda para hacer frente a las facturas. Esa ayuda provendrá de las administraciones públicas (apdo. 1 del

33 Ley Orgánica 6/2006, de 19 de julio, de reforma del Estatuto de Autonomía de Cataluña: $B O E, 172$, de 20 de julio de 2006. 
art. 6) o de las empresas que suscriban un acuerdo, bien en forma de ayudas a fondo perdido, bien en forma de descuentos «muy notables» (apdo. 3 del art. 6). Esta finalidad podría encajar en unas legítimas medidas asistenciales de Cataluña. Lo que no es admisible es que Cataluña disponga de un procedimiento propio para el corte del suministro, que imponga, en algunos casos, la prohibición de corte, aunque haya impago. En este sentido, la STC 62/2016 ha dicho que el establecimiento por parte del Código de Consumo catalán, de la prohibición de desconexión del suministro eléctrico o de gas, en aras a la protección del consumidor vulnerable, aplicable a las personas en situación de vulnerabilidad económica y a determinadas unidades familiares, así como la imposición de un deber de aplazamiento y/o fraccionamiento de la deuda pendiente con la «empresa suministradora», contraviene la regulación básica que se establece en la LSE. Este incumplimiento resulta de imponer a las empresas comercializadoras el suministro de electricidad pese al impago del suministro, estableciendo la prohibición de desconexión de modo incompatible con las previsiones básicas estatales, que han optado por un diseño de protección del consumidor vulnerable a través de la bonificación del precio del suministro. Y a continuación añade la STS 62/2016 lo siguiente: «Ninguna objeción podría efectuarse al desarrollo por parte del legislador catalán de medidas asistenciales consistentes en prestaciones económicas tendentes a evitar la interrupción del suministro de electricidad y gas a los consumidores vulnerables que reciban un aviso de interrupción conforme al art. 166.1 a) del Estatuto de Autonomía para Cataluña $»^{34}$.

El apdo. 1 del art. 6 de la Ley 24/2015 establece que las administraciones públicas deben garantizar el derecho de acceso a los suministros básicos de agua, gas y electricidad a las personas con riesgo de exclusión social. El apdo. 2 manda que se establezca un protocolo obligado de comunicación a los servicios sociales y de intervención de estos servicios previamente a la concesión de las

34 Estas son las medidas que contemplan las normas de otras comunidades autónomas: Decreto Ley 8/2014, de 10 de junio, de medidas extraordinarias y urgentes para la inclusión social a través del empleo y el fomento de la solidaridad en Andalucía (BOJA, 113, de 13 de junio de 2014); Decreto Ley 1/2016, de 10 de mayo, de medidas extraordinarias contra la exclusión social, del Gobierno extremeño (BOE, 146, de 17 de junio de 2016); Ley 10/2016, de 1 de diciembre, de medidas de emergencia en relación con las prestaciones económicas del Sistema Público de Servicios Sociales y con el acceso a la vivienda en la Comunidad Autónoma de Aragón (BOE, 14, de 17 de enero de 2017); y Ley 3/2017, de 3 de febrero, para paliar y reducir la pobreza energética (electricidad, agua y gas) en la Comunitat Valenciana $(B O E, 56$, de 7 de marzo de 2017). 
ayudas necesarias para evitar los cortes de suministro, en caso de impago por falta de recursos económicos.

De conformidad con el art. 131 de la Ley 39/2015, de 1 de octubre, de procedimiento administrativo común ${ }^{35}$, ese protocolo (cuando se apruebe) será de obligado cumplimiento, por dos vías alternativas: a) porque se aprueba como una disposición administrativa de carácter general (como norma reglamentaria), o b) porque la Administración pública y las empresas implicadas acuerdan que el protocolo les va a ser de aplicación (sólo a las empresas que lleguen a un tal acuerdo con la Administración pública, lógicamente) ${ }^{36}$.

En el apdo. 2 del art. 6, la ley dice que hay que comunicar a los servicios sociales (según establezca el protocolo), para evitar los cortes de suministro, por causa de impago. Se trata de una concreción de un principio que la ley llama de precaución. No dice la ley que no se pueda cortar el suministro aunque alguien no pague las facturas (como establece la LSE). El apdo. 2 del art. 6 de la ley quiere que haya una comunicación a los servicios sociales, para que el corte se pueda evitar, no porque esté prohibido. Si se pone esto en relación con los apdos. 1 y 3 , del mismo art. 6, se llega a la conclusión de que si alguien no paga la deuda del usuario con la empresa (la Administración pública o la empresa misma), entonces nada impide que se pueda cortar, tal como establece la LSE.

El apdo. 3 se refiere a los acuerdos (o convenios) con empresas de suministro (agua, electricidad y gas) para garantizar que ayudan a fondo perdido a las familias en riesgo de exclusión residencial o que les aplican descuentos muy notables. Es llamativo que se emplee en la Ley 24/2015 la forma imperativa: «Las administraciones públicas deben establecer los acuerdos o convenios». Es llamativo porque todo acuerdo o convenio requiere la confluencia de dos voluntades y, por tanto, el establecimiento de esos acuerdos depende, también, de las empresas implicadas. El apdo. 4 del art. 6 dice que "cuando la empresa suministradora tenga que realizar un corte de suministro debe solicitar previamente un informe a los servicios sociales municipales para determinar si la persona o la unidad familiar se

35 BOE, 236 de 3 de octubre de 2016.

36 Ese protocolo no ha sido aprobado aún. El Parlamento de Cataluña, mediante Resolución aprobada en el Pleno celebrado los días 9 y 10 de marzo de 2016 (Boletín Oficial del Parlamento de Cataluña de 16 de marzo de 2016), insta al Gobierno de la Generalitat a que desarrolle normativamente la Ley 24/2015, en punto a la obligatoriedad de solicitar un informe a los servicios sociales, antes de proceder al corte de suministro. 
encuentra en una de las situaciones de riesgo de exclusión residencial». Si la persona está en esa situación, el precepto establece que las administraciones públicas deben garantizar los suministros básicos (remite al apdo. 1 del art. 6) y deben aplicarse las ayudas necesarias para que no se genere deuda (apdo. 4). En ningún lugar se dice de modo explícito que quede prohibido el corte del suministro por impago, ni tampoco se establece que no se pueda cortar sin el informe previo.

El art. 6 de la Ley 24/2015 debe ser interpretado a la luz de la STC 62/2016, de 17 de marzo. El hecho de que el Gobierno español haya dejado fuera de su recurso de inconstitucionalidad frente a la Ley 24/2015 su art. 6 no significa que el precepto pueda ser interpretado en contra de la Constitución, tal y como lo ha sido por la STC 62/2016, en términos claros. Pues bien, el art. 6 no dice que pueda prohibirse a una empresa de suministro de electricidad que corte el suministro a quien incurre en alguno de los supuestos que, de conformidad con la legislación estatal, deben conducir a la interrupción del suministro.

Resulta de especial relevancia deshacer el equívoco de identificar, asimilar o equiparar los posibles efectos de la ausencia del informe previo del art. 6, apdo. 4, de la Ley 24/2015, con los efectos de la ausencia del informe a que se refería el apdo. 6, párrafo $2^{\circ}$, del art. 252-2, del Código de Consumo de Cataluña. Ese párrafo fue declarado inconstitucional. Recuérdese que el art. 252-4, apdo. 6, párrafo $1^{\circ}$, manda a las personas en situación de vulnerabilidad que pidan un informe a los servicios sociales al recibir un aviso de interrupción del suministro de electricidad o gas, en el plazo de diez días. El párrafo $2^{\circ}$ (que fue declarado inconstitucional por la STC 62/2016), decía lo siguiente:

En el caso de que no se haya presentado el informe de los servicios sociales básicos, sino únicamente su solicitud, la empresa suministradora suspenderá la interrupción del suministro hasta que éste se aporte, o transcurran dos meses desde que se le comunicó que se había solicitado.

El TC reputó que esa previsión se apartaba del procedimiento de corte del suministro regulado en las leyes básicas estatales de hidrocarburos y de electricidad, y declaró que era inconstitucional. Pues bien, en relación con el art. 6 de la Ley 24/2015 es importante hacer dos afirmaciones: a) el precepto no dice que no se pueda cortar el suministro si no existe ese informe previo; y b) no lo podría decir, porque resultaría inconstitucional, a la luz de la STC 62/2016, de 17 de marzo.

En su Dictamen de 21 de abril de 2016, el Consejo de Estado dice que el art. 6, apdo. 4, de la Ley 24/2015, no es inconstitucional si se interpreta que 
el informe no tiene la finalidad de impedir el corte de suministro, sino la de evitarlo mediante el otorgamiento de ayudas a las personas ${ }^{37}$.

El art. 5 de la Ley 9/2016, de 3 de noviembre, de reducción de la pobreza energética de Aragón ${ }^{38}$, lleva por encabezamiento, el siguiente: «Procedimiento para evitar la suspensión del suministro o proceder a su restablecimiento". El autor de la ley es consciente de que no puede establecer un procedimiento para el proceder al corte (eso es competencia del Estado), sino solo "para evitarlo»" ${ }^{39}$. La ley contempla ayudas a determinadas personas para que puedan pagar sus facturas energéticas. Cuando una empresa vaya a cortar el suministro, el usuario debe comunicar esa circunstancia a los Servicios Sociales competentes. Es entonces cuando el apdo. 3 de ese art. 5 establece lo siguiente:

Con el objetivo de asegurar la eficacia de las medidas de protección social establecidas en esta ley, existiendo acreditación de persona o unidad de convivencia en situación de vulnerabilidad o de especial vulnerabilidad o encontrándose la misma en tramitación, la empresa suministradora no procederá a la suspensión del suministro mientras se gestiona la concesión de la prestación económica que corresponda destinada al pago de la factura del consumo energético.

Se trata de una previsión con un alcance parecido o idéntico al del párrafo $2^{\circ}$ del apdo. 6 del art. 252-4 del Código de Consumo de Cataluña. En el caso catalán, mientras se tramitaba el informe, no se podía cortar el suministro (párrafo 2o del apdo. 6 del art. 252-4, del Código de Consumo catalán: párrafo declarado inconstitucional), en el caso aragonés (art. 5, 3 de la Ley 9/2016), no se puede cortar mientras se tramita la concesión de la prestación económica. Con independencia del juicio de constitucionalidad que merezca la ley aragonesa, lo importante es destacar que a diferencia de esas dos normas (que hablan expresamente de que no se puede cortar), el

37 Dictamen 149/2016: Recurso de inconstitucionalidad en relación con los arts. 2 (apdos. 1), 2) y 4)), 3, 4, 5 (apdos. 1), 2), 3), 4), 5), 6), y 9)), 6 (apdos. 3), 4) y 5)), 7, la disposición adicional, la disposición transitoria segunda y las disposiciones finales segunda, tercera y quinta de la Ley de Cataluña 24/2015, de 29 de julio, de medidas urgentes para afrontar la emergencia en el ámbito de la vivienda y la pobreza energética.

$B O E, 296$, de 8 de diciembre de 2016.

39 En el mismo sentido, el Real Decreto Ley 3/2015, de 15 de diciembre, del Gobierno de Aragón, de medidas urgentes de emergencia social en materia de prestaciones económicas de carácter social, pobreza energética y acceso a la vivienda (Boletín Oficial de Aragón, 243, de 18 de diciembre de 2015). 
art. 6 de la Ley 24/2015 no dice que no se pueda cortar si no se ha solicitado el informe ${ }^{40}$.

\subsection{El concurso para el suministro eléctrico en el Ayuntamiento de Barcelona}

A instancias de dos empresas energéticas, el Tribunal Catalán de Contratos del Sector Público anuló el concurso municipal para el alumbrado público y el suministro de electricidad al Ayuntamiento, pues la cláusula relacionada con la pobreza energética que incorporaba no se ajustaba a la legalidad. En la Resolución de 1 de marzo de 2017, el Tribunal reconoce que resultan «loables y encomiables» las «buenas intenciones del ayuntamiento» para reducir la pobreza energética, pero «sus decisiones están sujetas a la aplicación de la legalidad sin ningún otro condicionante como garantía del Estado de derecho y en aras a garantizar la necesaria seguridad jurídica» ${ }^{41}$. El Tribunal entendió que una cláusula de este tipo debe estar bien definida, mientras que en este caso «no aporta las obligaciones a ejecutar por el contratista de una manera clara e inequívoca». De esta forma, el Tribunal consideró que las compañías que optaban al concurso "no conocen sus obligaciones», pues no se había firmado el correspondiente convenio en materia de pobreza energética con el Ayuntamiento de Barcelona. El Tribunal consideró también que el Ayuntamiento no había fijado un precio a la parte del contrato relacionada con la pobreza energética, por lo que no podía considerarse un contrato público. La cláusula social incluida en el pliego de condiciones resulta así contraria al TRLCSP. Una de las empresas alegaba que resultaba discriminatorio obligar a asumir a algunas compañías determinados compromisos respecto a los clientes en situación de vulnerabilidad cuando las pequeñas comercializadoras de electricidad que se han presentado al concurso, al operar en el mercado libre, no tienen estas exigencias.

40 A la necesidad de un informe previo antes de proceder al corte se refiere la Ley 10/2016, de 7 de junio, de Reforma de la Ley 6/2015, de 24 de marzo, de la Vivienda de la Región de Murcia, y de la Ley 4/1996, de 14 de junio, del Estatuto de los Consumidores y Usuarios de la Región de Murcia (BOE, 167, de 12 de julio de 2016); en el mismo sentido, la Ley $2 / 2017$, de 3 de febrero, por la función social de la vivienda de la Comunitat Valenciana (BOE, 56, de 7 de marzo de 2017).

41 Resolución 44/2017, de 1 de marzo, en http://tribunaldecontractes.gencat.cat/ 


\section{CONCLUSIONES}

La defensa de los consumidores de electricidad es una parte integrante de los esfuerzos por construir un Mercado Único de la Energía (MIE) en la Unión Europea. El Mercado Único de la electricidad no consiste solo en la eliminación de barreras a la libre competencia entre empresas eléctricas, sino que incorpora preocupaciones propias del servicio público, como la protección de los consumidores vulnerables.

El legislador español optó (primero en 2009, luego en 2013 y definitivamente a finales de 2016) por el diseño de un bono a favor de determinados consumidores, que cubre la diferencia entre la tarifa de último recurso y el precio que pagan ordinariamente los pequeños consumidores (el llamado precio voluntario para el pequeño consumidor). Lo relevante es que el bono social ha de ser financiado por las empresas eléctricas. El bono social es una obligación de servicio público que pesa sobre las empresas de comercialización eléctrica. A pesar de que el bono es un bono social, su financiación corre a cargo de las empresas eléctricas. Este bono no debería ser denominado bono social, sino bono eléctrico. Si el bono fuese verdaderamente social, su financiación habría de correr a cargo de los presupuestos de aquellas administraciones públicas con competencias en la protección (social) de los clientes vulnerables. El autor del vigente bono social explica que ha pretendido impedir que su financiación se traslade a los precios de electricidad, para así evitar que al tiempo que se beneficia a los clientes vulnerables (mediante el bono), se les perjudique mediante un aumento del precio por la necesidad de financiar tal bono. Por esa razón se decidió no hacer recaer la financiación del bono sobre las empresas de red (transporte y electricidad): de esa manera la financiación del bono no se convierte en un coste del sistema y no existirá la tentación de trasladarlo a los peajes.

Hasta aquí, el argumento (en síntesis) del autor del nuevo sistema de bono social. Sin embargo, aunque la solución arbitrada (obligación impuesta sobre los comercializadores) evitase efectivamente que el Gobierno traslade el importe del bono social a los peajes, no existe garantía de que, de una forma u otra, de modo directo o indirecto, el bono social que pesa sobre las comercializadoras termine siendo trasladado a los consumidores. Como se denuncia de modo generalizado, la estructura del precio que pagan los clientes españoles de electricidad carece de la necesaria transparencia, pues pocos componentes de ese precio son referibles al coste de la electricidad misma. Esta situación no contribuye satisfactoriamente a la creación de competencia mediante el envío de las señales adecuadas al consumidor. En este contexto, la financiación del bono social, en la medida en que se hace recaer sobre uno de los sujetos del sistema eléctrico (las empresas comercializadoras), es una 
fuente adicional de distorsión del sistema. Las circunstancias que convierten a un consumidor en vulnerable no tienen que ver con el sistema eléctrico; son circunstancias ajenas al sistema eléctrico (como, por ejemplo, la situación de viudedad). Siendo eso así, para que una realidad ajena al sistema no termine perjudicando al sector en su conjunto, parecería que una manera más justa y equitativa de financiar el bono sería su financiación con cargo a los presupuestos. Entonces el bono devendría verdaderamente social y debería ser soportado por las administraciones públicas con competencias (y las correspondientes obligaciones) en materia de política social, como la defensa de consumidores y usuarios. Consideraciones parecidas a las anteriores deben hacerse a propósito de la financiación de los impagos de aquellos consumidores vulnerables severos, que tienen ahora la consideración de suministros esenciales desde la reforma de 2016.

Si bien la obligación de subvenir a la necesidad de quien no puede pagar su factura eléctrica satisface un principio elemental de justicia material, es importante que el modo de atajar ese problema se haga sin merma de dos pilares de la convivencia, jurídicamente salvaguardada. En primer lugar, que los contratos (como los contratos de suministro de electricidad) han de cumplirse en sus términos, sin que sea admisible que el ordenamiento debilite la protección que se merecen. En segundo lugar, que no debe hacerse recaer sobre una parte del sistema (ya sean las empresas eléctricas, ya sean los consumidores de electricidad) la solución a problemas generados y pertenecientes al exterior de ese sistema (ajenas al sistema eléctrico son las circunstancias que convierten a un consumidor en consumidor vulnerable).

La protección del consumidor eléctrico constituye propiamente una competencia referible al régimen jurídico básico de la energía, como la jurisprudencia constitucional se ha ocupado de reiterar en varias ocasiones. La configuración de la protección del consumidor vulnerable por la vía de la ayuda social, más allá del vigente bono eléctrico, amplía las posibilidades de actuación de las comunidades autónomas.

Existe un borrador del Real Decreto que introduce claridad en algunos aspectos, por ejemplo en la determinación de quiénes son clientes vulnerables. Sin embargo, son numerosos los puntos que permanecen oscuros. Algunos aspectos que en la LSE parecían estar claros, son oscurecidos por el borrador. En concreto, el borrador introduce una distinción dentro de los consumidores vulnerables severos, inexistente en la LSE: los vulnerables severos, a secas, y los vulnerables severos en riesgo de exclusión social (los cuales no constituyen una subcategoría solo por la existencia de ese riesgo sino porque su factura está siendo pagada, al menos en el $50 \%$, por alguna Administración pública). Lo que se percibe en este borrador del Real Decreto (y se trasluce, un tanto, en el Real Decreto Ley 7/2016) es que el legislador trata de compeler a las 
administraciones autonómicas y locales a que paguen la factura eléctrica (al menos parcialmente) de aquellos consumidores vulnerables severos. En otras palabras, aun cuando parecía que el Real Decreto Ley 7/2016 creaba, por primera vez, un suministro esencial a favor de consumidores-personas físicas, a las cuales, por su condición de esenciales, no se les podría cortar el suministro, en realidad esa nueva categoría de suministro esencial es un instrumento de coerción impuesto sobre las administraciones con competencias en asuntos sociales. Si esas administraciones (autonómicas y locales) no se hacen cargo de, al menos, la mitad de la factura, entonces se les podrá cortar el suministro por parte de la empresa comercializadora. 
